\title{
REMARKS ON THE CAUSE
}

\section{OF \\ CLOSURE OF THE VALVES OF THE HEART.}

BY

\author{
WILLIAM O. MARKHAM, M.D.,
}

PHYSICIAN TO ST. MARY'S HOSPITAL.

Received Jan. 2nd.-Read March 12th, 1861.

In reflecting upon the causes by which the closure of the auriculo-ventricular valves of the heart is effected, it occurred to me that the explanation of the physiological fact generally received was insufficient to account for the whole of the phenomena which attend it. A reference to the opinions held by physiologists respecting the causes of the closure of these valves will, I think, satisfy every one that a complete explanation of the fact has not yet been given.

With regard to the mode of closure of the valves in question, physiologists, are, I believe, at the present moment generally agreed. The received opinion is this - the closure is effected at two different periods of the heart's action, and may therefore be divided into two stages. During the first stage (which corresponds to the period of the ventricular diastole and the passage, of course, of the blood from the auricle into the ventricle) the valves are gradually raised upwards towards the auriculo-ventricular orifices, pari passî with the distension of the ventricles, so that their free borders are made to approach each other. The second stage of the closure of the valves corresponds, in time, with, and is effected by, the ventricular systole; the loose borders of the 
valves, already raised upwards towards each other, are suddenly and forcibly brought together by the pressure of the blood upon their ventricular surfaces. In this way, and by the simultaneous contraction of the papillary muscles, the complete closure of the opening is perfected and maintained during the time of the ventricular systole.

Now, as far as I have been able to learn, the cause which is effective in raising the valves upwards towards each other during the first stage of the closure above referred to has not been correctly explained. A little consideration, indeed, will, I think, satisfy every one that the explanation usually given of the fact cannot be correct. The matter is disposed of as follows in Todd and Bowman's 'Physiology :- "When the blood accumulates in the ventricles it pushes up the auriculo-ventricular valves towards the auricle, until their several portions come in contact with each other and close the orifice." The latest writer on the heart's actions, Dr. Halford, writes as follows on this head:- "The auricles contracting on the blood, the force of their contraction is transmitted by the blood in all directions, separating the flaps of the valves, distending the ventricles, and (the semilunar valves being shut down) pressing as much upwards and backwards, as downwards and onwards. The force, not being sufficient to raise the semilunar valves, is expended in distending the ventricles and raising and closing the auriculo-ventricular valves."

The views of these authors are, I believe, the generally accepted explanation of the fact. The flow of blood from the auricle and the force of the auricular contraction, as it is supposed, force the valves upwards and into contact during the diastole of the ventricle.

It is evident, however, that this explanation is incorrect, and that, in fact, the stream of blood flowing from the auricle into the ventricle cannot possibly raise the valves upwards. During life the size of the auriculo-ventricular orifice is, of necessity, exactly adapted to the size of the current of blood which passes through it during the ventricular diastole, and, consequently, the current of blood 
passing from the auricle into the ventricle, whatever be the degree of force which drives it along, is in immediate contact with the auricular surface of the valves, and must press with as great force upon the upper as it does upon the under surface of the valves. Such a force could not, therefore, effect the elevation of the valves towards each other, i.e. their closure, during the ventricular diastole. The truth is that the pressure of the current of blood is greater upon the upper than upon the lower surface of the valves, and would therefore rather tend to depress than raise the valves. And there is another objection to the usually received explanation. At the conclusion of the ventricular systole the valves, we must suppose, are brought into close contact with the inner walls of the ventricle; consequently, the current of blood Howing into the ventricle during its diastole would rather tend, than otherwise, to keep them closely applied against the ventricular walls.

Such considerations satisfied me that the valves must be raised up towards each other during the ventricular diastole by some other agency, and on investigation of the subject $I$ ascertained what $I$ have no doubt is the true explanation of the phenomenon.

The valves are raised from the walls of the ventricles towards each other during the ventricular diastole by the agency of elastic tissue, which is so disposed within them as to render the action at once simple and effective. The auriculo-ventricular and the semilunar valves of the heart have all, essentially, the same structure. They are formed of two distinct parts - an elastic membrane, and a number of inelastic, white, fibrinous cords, united together by elastic membrane. In the case of the auriculo-ventricular valves (and I am speaking of the structure as observed in a bullock's heart) a thickish layer of elastic membrane may be readily dissected off from the auricular surface of the valves; this layer moves freely on the lower layer of the valve, except at the free border of the valves, where it becomes intimately connected with the lower layer of the valves. This elastic layer is retractile in all directions, but its fibres appear to 
run chiefly in a direction from the attached towards the free borders of the valves. The lower or ventricular layer of the auriculo-ventricular valves consists of strong cords of white, fibrous tissue-the continuation of the chordæ tendineæ into them-subdividing and diminishing in size as they branch out in the valves. These branching white, fibrous cords are united together by elastic tissue, but chiefly by their upper auricular borders only, the lower border of the cords projecting from the under surface, and giving it a rough, furrowed appearance. (Dr. Broadbent, the Curator of St. Mary's Hospital Medical School, has, at my request, made a series of dissections of the valves of bullocks' hearts, and I subjoin his detailed description of their structure.)

From this disposition of the elastic tissue we may fairly conclude--- that when its elasticity is called into play, it must tend to draw the free borders of the valves towards their attached borders; and that, inasmuch as the elastic fibres are chiefly placed in the upper layer of the valves, they must necessarily tend to approximate the two borders of the valves in the direction of their auricular surface. This is, in fact, what happens. When the ventricles are emptied, $i . e$. at the end of ventricular systole, the valves are brought down and pressed against the internal walls of the ventricles, and, as we must conclude, the elastic tissue put on the stretch. But during ventricular diastole, as the blood flows into the ventricles, the weight (the specific gravity) of the valves is diminished by the fluid, so that the elastic fibres have power enough to draw the valves upwards towards each other and to close partially the auriculo-ventricular orifice, the valves rising up in the ventricle pari passu with its dilatation. I may add that the elasticity of the endocardial membrane surrounding the auriculo-ventricular valves also assists in the elevation of the valves.

Such is what may be called a theoretical description of the mode of action of the valves, deduced from their anatomical structure. But the simplest experiments will satisfy any observer that no other explanation of the fact is 
possible. When the auricle is removed from its ventricle, and water poured into the ventricle, it will be found that the valves not only gradually rise upwards towards the auriculo-ventricular orifice whilst the water is flowing into the ventricle, but that they remain in an upraised position when the stream is arrested, and that they will, if depressed, again arise towards each other when the pressure is removed. Now, as their specific gravity is considerably greater than that of water or of blood, it is manifest that they would weither rise up towards each other in the water nor maintain that elevated position unless some force overcame their gravity; and it is equally evident that no other force than that of elastic tissue could, from the nature of the case, be in operation. Again, when the free borders of the valves are separated from their attachments to the chordæ tendineæ, the valves will be found to have a natural tendency to curl over in the direction of their auricular surface. In the case of a dog I have thus seen the anterior mitral valve actually curl up into the auricle like a scroll of paper.

As corroborative of this view of the cause of closure of the auriculo-ventricular valves, I may add that we find an exactly similar anatomical disposition of parts in the semilunar valves, but with this necessary difference, that in their case the elastic fibres are spread over the ventricular surface of the valves. The purpose of this elastic tissue is manifestly the same here as in the former case, viz., to assist in drawing the valves away from the arterial walls (against which they must be closely pressed during ventricular systole), and thus in bringing them together, or, rather, of putting them into a position of being readily brought together, when the ventricular systole ceases.

I will, in conclusion, suggest that this view of the mode of closure of the valves may explain some facts in diagnosis which have hitherto puzzled the physician, as, for instance, the existence of a cardiac murmur heard during life in cases in which the valves have been found after death, to all appearance, competent. In such a case I would suggest that the elastic element of the valves has undergone some 
pathological change, whereby its elasticity has been impaired or destroyed, and, therefore, that the valves were no longer able to rise up freely towards each other during ventricular diastole. In consequence of such imperfect action a certain amount of regurgitation must necessarily occur at the commencement of the ventricular systole, and, consequently, a murmur be excited. The fact also shows that, to prove the capacity of the auriculo-ventricular valves for effective closure during life, we must ascertain the condition of their elastic powers after death, in the manner above described, viz., by removing the auricles of the heart and filling the ventricles with fluid. The greater or less degree of readiness with which these valves rise in the fluid will indicate the condition of their elastic tissue.

\section{Appendix.}

Since the above paper was read to the Society I have satisfied myself that there is one other element of force which either does, or may, play a part (at a given moment) in the closure of the auriculo-ventricular valves. This force is the elasticity of the distended ventricle itself, called into action by the distending force of the auricular systole; and the given moment is that instantaneous period of time which intervenes between the conclusion of auricular systole and the commencement of ventricular systole. The force of the auricular contraction (which, as we have seen, comes into play during the second period of the ventricular diastole) drives forward the blood, and not only dilates, but also forcibly stretches, the ventricles. Consequently, when this distending force (the auricular contraction) ceases, the elasticity of the distended ventricles comes into play, reacts on their contents, and therefore necessarily presses the blood against the ventricular surface of the auriculoventricular valves. By this pressure these valves are brought into perfect contact, and the closure of the auriculoventricular orifice completely effected. This is what we 
must, theoretically, admit to take place during that minute interval of time which occurs between the cessation of auricular and the commencement of ventricular systole.

\section{Dr. Broadeent's Account of the Structure or the Valves of THE HEART.}

The auriculo-ventricular and arterial valves of the heart are essentially similar in structure, and are made up of two distinct layers, slightly moveable one on the other, except near the margin where they coalesce to form the thin membranous edge; of these layers, one is elastic and smooth, the other comparatively inelastic, and presenting fibrous, trabeculæ running in various directions.

When one of the flaps of the mitral or tricuspid valve is examined, its superior or auricular surface will be seen to be perfectly smooth and continuous with the endocardial lining of the auricle, without any other line of demarcation than the difference in colour between the subjacent muscular fibres of the auricle and the fibrous tissue of the valve. The ventricular surface, on the contrary, is marked by numerous fibrous trabeculæ, which radiate in various directions from the chordæ tendineæ. The large cords implanted into the body of the valve spread out on its under surface into many strong bands, which pass chiefly towards the attached border, and are firmly fixed in the fibrous ring which surrounds the auriculo-ventricular opening; some, however, go towards the free margin, and seem to receive the fine ramifications of the delicate chordæ tendineæ inserted into, and near, the extreme edge of the valve. On this aspect the line of origin of the valve is marked by a distinct groove, and its fibrous trabeculæ are perpendicular to the muscular pillars of the ventricle.

If incisions be made through the endocardium of the auricle, and carried down upon the valve, a thin, transparent 
membrane is readily raised from the muscular substance of the auricle, and from the superior surface of the valve to near its margin. This is extremely elastic, and, on microscopic examination, is found to consist chiefly of a network of very fine, elastic fibres, having a general direction from the attached to the free border of the valve. A second membrane may readily be separated almost equally elastic, and containing much elastic tissue, with a similar arrangement; this is not continuous over the muscular fibres of the auricle, but seems to terminate in them; and in a bullock's heart delicate slips of muscle are continued for a distance of one fourth or three eighths of an inch into it.

There is now left the layer formed by the radiating divisions of the chordæ tendineæ, united to the preceding membrane by connective tissue, containing many elastic fibres; the fibrous bands themselves also being connected together by similar material. These bands are made up almost entirely of white, fibrous tissue, they are absolutely inelastic, and render the layer of the valve into the composition of which they enter comparatively so. The endocardium of the ventricle extends as a very delicate membrane over the under surface of the valves. The semilunar valves are smooth on their ventricular or convex surface, the endocardium here also passing continuously over this aspect of the valve, and constituting a strong, elastic mem. brane, in which the fibres have a general direction from the attached to the free border of the valve. There is a second layer containing much elastic tissue, and when this is removed there remains, at the concave aspect of the valve, a membrane presenting an arrangement of strong, fibrous bands stretching transversely across from one angle to the other, and forming at the centre of the valve an imperfect raphé. These bands are inelastic, but are connected with each other by tissues containing a considerable proportion of the elastic element. 